\title{
O MINDSET DA ADMINISTRAÇÃO DE EMPRESAS DE FUTURO: ADMINISTRAÇÃO DIGITAL CONTEMPORÂNEA
}

\section{ARTIGO ORIGINAL}

MARTINS, Geisse ${ }^{1}$

OLIVEIRA, Maria Inês Vasconcelos Rodrigues de ${ }^{2}$

SANTOS, Tatiana dos ${ }^{3}$

MARTINS, Geisse. OLIVEIRA, Maria Inês Vasconcelos Rodrigues de. SANTOS, Tatiana dos. 0 mindset da administração de empresas de futuro: Administração digital contemporânea. Revista Científica Multidisciplinar Núcleo do Conhecimento. Ano 05, Ed. 11, Vol. 21, pp. 05-15. Novembro de 2020. ISSN: 2448-0959, Link de acesso: https://www.nucleodoconhecimento.com.br/administracao/administracaodigital

\section{RESUMO}

Este trabalho tem como objetivo refletir sobre a administração e a gestão na era digital. Uma situação real e que não pode ser retrocedida é a de que as empresas estão de frente para um grande número de mudanças que exigem dos administradores,

${ }^{1}$ Mestrando em Tecnologias Emergentes em Educação pela Miami University of Science and Technology (MUST). Especialista em Neurociências e Aprendizagem, Psicopedagogia, Coordenação/Supervisão Escolar, Inspeção escolar com ênfase em Educação Especial Inclusiva, Pedagogia Empresarial, MBA em Gestão Estratégica. Graduado em Pedagogia e Telecomunicações.

${ }^{2}$ Graduada em Direito pela UFMG e Pós graduação em Direito Empresarial pela PUC MINAS. Mestranda em Tecnologias Emergentes em Educação pela Miami University of Science and Technology.

${ }^{3}$ Orientadora. 
gestores ou líderes, habilidades em lidar com questões relacionadas ao digital e não somente e competências meramente técnicas da administração clássica ou tradicional. Como essas mudanças são estruturais, algumas de ordem social, econômica, política, e com ênfase tecnológica, tendem a influenciar não somente as decisões, mas toda a ecologia das empresas. Se num passado próximo as atenções, os planejamentos e as decisões dos executivos das empresas estavam centradas em pontos específicos, já matriciados e apoiados por teorias clássicas, cujas aplicações eram bem-sucedidas, agora, essas matrizes não podem mais dar conta dessa nova revolução tecnológica. Outros elementos figuram no dashboard dos administradores que tem o futuro como ponto de partida para suas organizações. O mindset das empresas de futuro se compõe de um mosaico de novos elementos e que possui uma dinâmica própria, disforme, fluída e altamente cambiante. Buscando compreender todos esses cenários e como a visão de autores que versam sobre o tema, o presente artigo pretende responder questões que se apresentam e que precisam de uma análise mais direcionada, além de trazer uma reflexão e análise sobre esse tema que se apresenta na contemporaneidade.

Palavras-chave: administração, tecnologias, mindset, decisão, empresa de futuro.

\section{INTRODUÇÃO}

O universo das organizações, há décadas, passa por transformações estruturais. O que se conhece por ondas ou fenômenos mundiais, de alguma maneira tem impactado profundamente dentro das organizações e em suas maneiras de administrar. A última onda, conhecida como a onda da tecnologia da informação e do conhecimento, desde a década de 1970, vem impulsionando novas formas de administrar e gerir as organizações.

Se, no passado matéria-prima, estoques, pessoas e um mercado consumidor ávido por produtos, eram considerados o esteio para que as organizações e suas formas de administrar pudessem garantir sobrevivência e alguma certeza de futuro, hoje, não mais. Liderar na era digital requer uma mudança radical frente a esses, já obsoletos, conceitos de um passado ainda recente em que a ciência da administração apoiava- 
se em conceitos anteriores, como capital social e humano, bens de capital, entre outros e que de alguma maneira estes lhe garantiam longevidade com certo conforto.

Com o advento das novas tecnologias de informação e também de conhecimento, elaborar uma visão digital das empresas exige dos executivos de administração um certo contorcionismo para que possam, de acordo com seus planejamentos, objetivar as metas das organizações. Estas cada vez mais possuem estreitamento no uso de recursos com alargamento da reinvenção amiúde de seus planos de negócios, bem como a necessidade de estarem alinhadas com as perspectivas de mercado ao mesmo tempo em que precisam lidar com novas demandas de seus clientes.

Conduzir a transformação do analógico para o digital, desenvolver capacidades de liderança tecnológica, reinventar modelos de negócios, administrar disrupção e gerir conhecimento são habilidades agora incorporadas no dashboard[4] dos administradores de empresas de futuro.

Mas é o que vem a ser uma empresa de futuro? As empresas tradicionais são valoradas pelos produtos que produzem, por exemplo, uma empresa que explora e produz petróleo tem como ativo dentre outras coisas a quantidade de óleo já processado que produz e que pode vender. $\mathrm{O}$ ativo de uma empresa produtora de refrigerantes, por sua vez, é o quanto se fabrica, vende e a sua expertise em logística, já em uma mineradora, o quanto se extraí em minerais. Com o advento da tecnologia da informação e do conhecimento, surgiram as empresas de futuro. Estas possuem seu ativo em coisas intangíveis, por exemplo, a gigante Google vale o quanto de informação que consegue processar e minerar[5], ou seja, o que tem valor numa empresa de tecnologia como a Google é a sua capacidade em lidar com a gigantesca montanha de dados e as pessoas (colaboradores) que sabem minerar essas informações, transformando-as em valor para o seus clientes e o mundo. Na mesma direção e sentido a Microsoft, a Apple, e a Amazon não possuem bens tangíveis para a comercialização, mas sim dados e informações processadas que podem representar valor de mercado. Para se ter uma ideia do valor desse capital, de acordo com Emerson Alecrim (2020), o valor de mercado da Apple, em 2020, é de US\$1,5 trilhão, o que corresponde ao PIB de um país como o Brasil. 
Tendo em vista esse cenário, nos últimos 10 anos, houve uma mudança radical no meio empresarial, inúmeros cenários (econômicos e históricos) apresentaram-se para os gestores e líderes das organizações. As novas tramas da já complexa competividade estão, cada vez mais, entrelaçadas por fatores sociais, políticos e culturais. Somando-se a isso, há a inovação que se apresenta com uma infinidade de facetas e dimensões ainda não totalmente descobertas. Entende-se aqui, que inovação não se esgota somente na criação ou ampliação de novos mercados, mas sim em outras formas de servir e saciar os mercados, sobretudo mercados em que a tecnologia e o conhecimento são agora o combustível de toda essa nova engrenagem.

Com efeito, alguns questionamentos apresentam-se nesse contexto: Quais os desafios e as ações que a organização ou a instituição pode adotar para maximizar seus resultados e minimizar impactos frente a um ambiente em constante mudança? Qual o papel da gestão nesse processo? Frente a esses questionamentos, o presente artigo tenta compreender e responder tais questões por meio de análise bibliográfica que versa sobre o tema e que poderá trazer luz às indagações.

\section{TECNOLOGIA: ADAPTAR-SE OU NÃO?}

Vamos direto ao ponto. A tecnologia é ponto fulcral do momento. Com absoluta certeza há outros eventos mundiais acontecendo, desde descobertas interessantes, economia compartilhada, novas profissões e novos produtos. Mudanças em fatores micro e macroeconômicos, fatores sociais e, também perpassando pela pandemia de COVID-19, causada pelo vírus Sars-CoV-2. Para as organizações essa mudança radical nos processos vem causando mudanças consideráveis nos processos internos e externos, o que exige dos administradores, gestores e líderes muito mais que apenas conhecimento técnico sobre administração clássica ou tradicional para o enfrentamento dos desafios propostos da atualidade.

Quase como que numa profecia Druker (1968 p. 57) afirmou:

Antes de mais nada os homens de empresa terão de aprender a entender a dinâmica da tecnologia e a prever a direção e a velocidade da mudança tecnológica. Quando a nova tecnologia era criada pelo 
inventor isolado que trabalhava fora da economia, não havia necessidade alguma desse entendimento. Se, entretanto, uma economia em funcionamento quiser ser capaz de promover inovação e mudanças rápidas, seu homem de empresa terá necessidade de prever a tecnologia e aproveitar as oportunidades oferecidas pelos desenvolvimentos tecnológicos.

\subsection{UM PASSADO NEM TÃO DISTANTE: MATRIZ DE ANSOFF E MATRIZ BCG}

Para tentar compreender, ao menos parte do que está acontecendo, faz-se necessária certa digressão. Num passado próximo, os cenários apresentados pelo mercado, via de regra, figuravam como em uma partida de xadrez, na qual as incógnitas estavam centradas, em grande parte, na administração de matéria-prima, estoques, pessoas, nos mercados e seus consumidores. A vantagem competitiva tinha como ponto axial fazer e entregar algo novo que pudesse ser compreendido como valor percebido para saciar os desejos dos consumidores. Ainda nesse contexto, um bom plano de negócios que fosse possível posicionar estrategicamente a empresa numa matriz, como determinou Ansoff (1990), era fundamental.

Figura 1 - Matriz de Ansoff

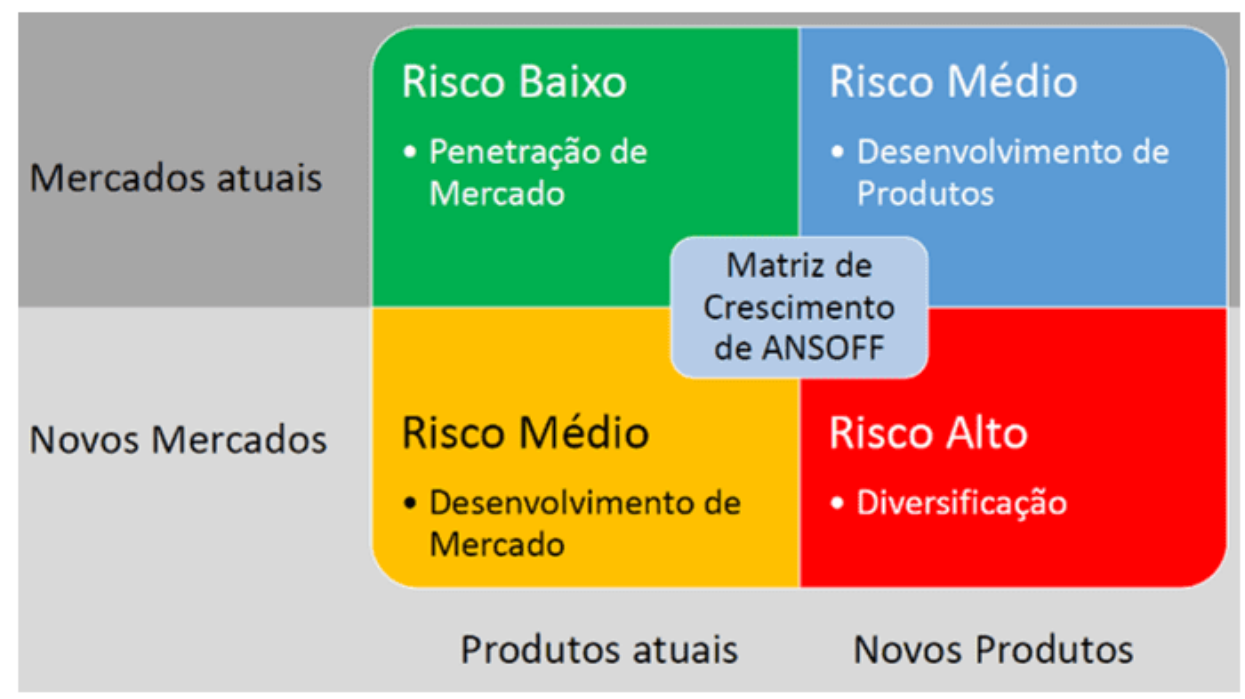

Fonte: o autor com base em Ansoff (1990) 
Ou, como propôs Kaplan e Norton (1992), utilizando outra matriz, denominada de BCG, e de acordo com o criador Daniel Castelo (VALUE BASED MANAGEMENT.NET, 2019), para uma empresa tradicional ter o sucesso esperado, é necessário possuir um portfólio de produtos com taxas distintas de crescimento e diferentes participações de mercado. Segundo Castelo (VALUE BASED MANAGEMENT.NET, 2019) a composição desse portfólio é intrinsicamente uma função de equilíbrio entre fluxos de caixa. Produtos ou serviços de alto crescimento exigem oxigenação com aporte de capital (dinheiro) para crescer efetivamente. Produtos e serviços de baixo crescimento devem sempre que possível gerar excesso de caixa ou ao menos um bom colchão de liquidez. Em suma ambos são fundamentalmente necessários e se agrupam simultaneamente.

Figura 2 - Matriz de BCG

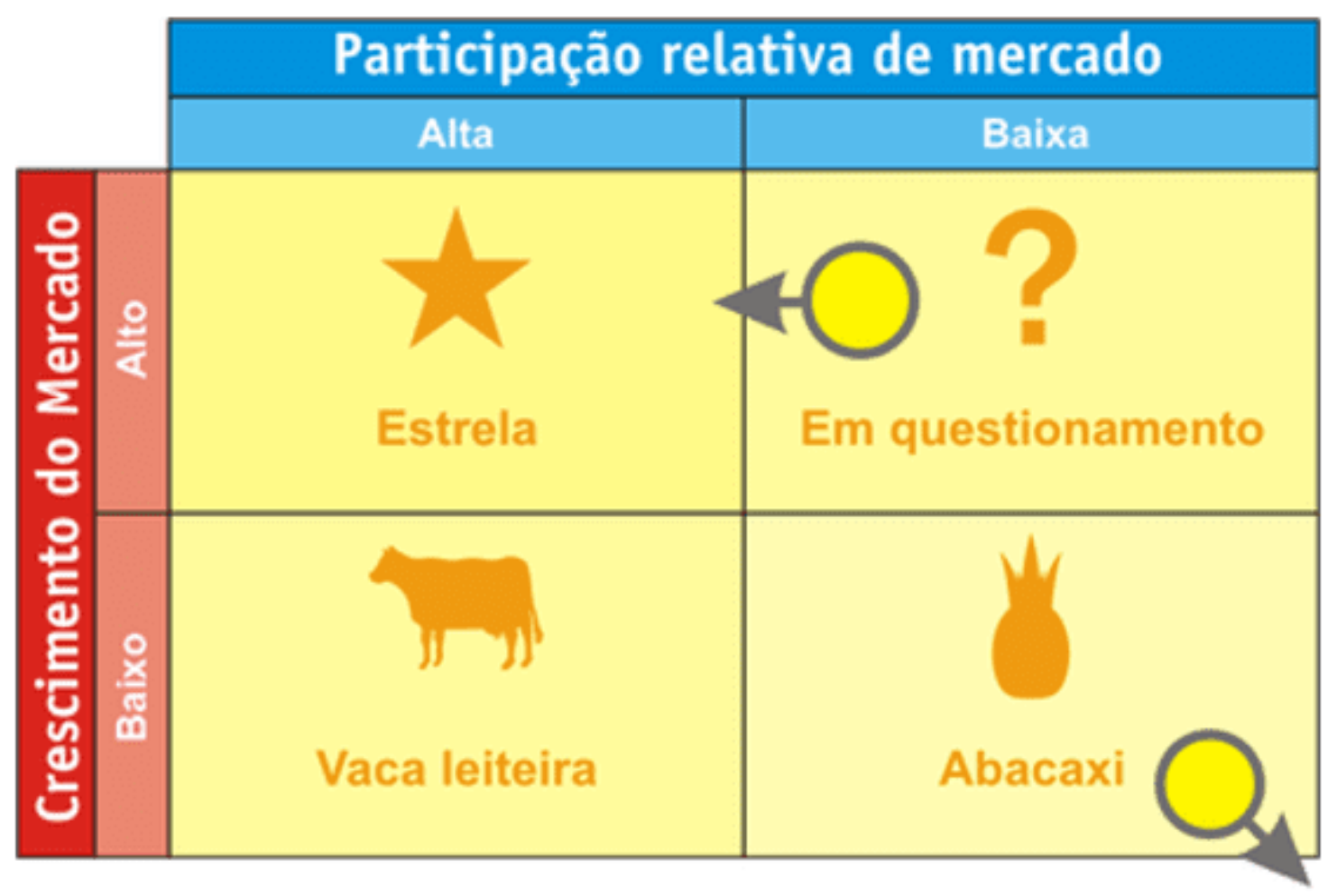

Fonte: Rabelo (2006)

Desconsiderando as vantagens e desvantagens da aplicação dessas matrizes, de certo que a tecnologia e sua dinâmica lancinante representam uma variável 
inconstante nessa equação. Ademais, nem mesmo Ansoff ou Castelo se aprofundaram no que se refere a tecnologia como ponto de impacto nesses cenários. Nem tão pouco o The Balanced Scorecard[6] tinha a pretensão ou capacidade de prever com exatidão a certeza das incertezas.

Fato é, que quando se instauram tecnologias da informação e do conhecimento, tudo isso que estava proposto torna-se inócuo, pois muitas das vezes tais metodologias ou ferramentas de gestão não são aderentes ao que se tem de administrar em uma empresa de futuro.

\subsection{A ADMINISTRAÇÃO EM EMPRESAS DE FUTURO}

Um bom exemplo disso é a administração dos custos de produção na indústria 4.0[7], que se utiliza de robótica e inteligência artificial; os sistemas de logísticas que se apoiam em algoritmos e se balizam nos conceitos de Just In Time; o capital intelectual dessas empresas (possuem um altíssimo "turnover" ou como é chamada de renovação de ideias) que fazem parte da Gestão do Conhecimento e que tem como espinha dorsal não somente atrair novos talentos, mas também reter o conhecimento e disseminar por toda a organização e até mesmo para a comunidade em seu entorno. Grande parte das empresas precisam aderir ao que é denominado, economia compartilhada (os papeis de concorrentes e parceiros agora se confundem com a empresa e se alinham com o planejamento estratégico), o tele trabalho já não é uma visão de futuro, é uma constante em um grande número de empresas que compreendem que não é posto estacionário de trabalho que gera valor ou que atinge os resultados esperados de assertividade, eficiência e eficácia dos colaboradores. Em síntese, pode-se afirmar que o digital trouxe novas formas de se fazer o que era feito antes e com resultados diametralmente opostos em relação ao que era visto ou percebido no passado.

Harmoniza-se com essa fundamentação, as considerações de Westman, Bonnet e McAfee "A onda tecnológica vem sendo construída há muito tempo, mas ganhou um ritmo muito mais acelerado nos últimos anos" (2016, p. 15). Ainda na visão desses 
autores, no livro intitulado Liderando na Era Digital (2016), há quatro níveis de maestria digital

Figura 3 - Quatro níveis de Maestria Digital

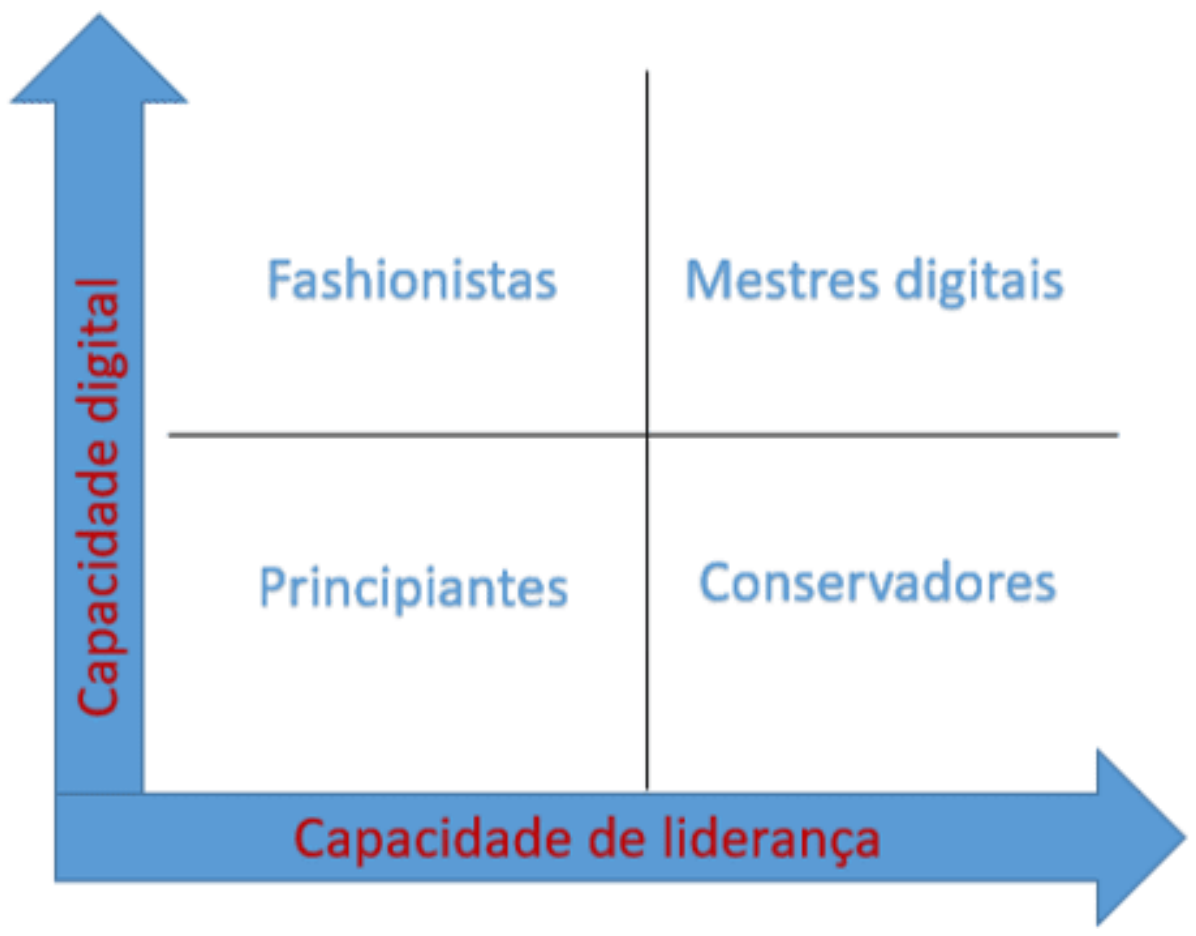

Fonte: o autor, com base em Westerman, Tannou, Bonnet, Ferraris e McAfee (2012 apud Westman, Bonnet; McAffe, 2016, p. 29)

Neste ponto, é importante ressaltar que diante do que o mundo passa na conjuntura atual, como o que acontece durante a pandemia da covid-19, e o porvir das incertezas pós-pandemia, nada é tão certo quanto a indefinição. A realidade das empresas tradicionais ou analógicas foi alterada, assemelhando-se às características das empresas de futuro, sendo algumas delas elencadas a seguir:

- Trabalho remoto: é certo que o trabalho remoto se configurou como uma alternativa viável e necessária em vista do distanciamento social e, agora, ficou provado que não é locus fixo de um colaborador que determina sua produtividade. Reduzir os custos fixos de aluguel, de espaços e postos de trabalho já se estabeleceu prioridade primeira, com o Home Office ou o 
Coworking essa prioridade em reduzir custo se estabelece como ordem primeira.

- Internet como meio e não como fim: sabe-se agora que a internet é um meio poderoso e as organizações precisam repensar sua utilidade e aplicabilidade. Deve constar nos planejamentos de investimentos e pesquisa para que as empresas se apropriem de seu potencial de utilização como vantagem competitiva. O comércio eletrônico (B2B e o B2C) não são apenas quimeras e precisam fazer parte da estratégia e também do plano de marketing.

- Tudo na Nuvem: aprendeu-se rapidamente que as plataformas (softwares, programas, planilhas e afins), que antes eram armazenadas em estações fixas de trabalho, agora estão sendo compartilhadas e salvas na nuvem ou estão em processo de migração para 0 digital. Com o propósito de garantir escalabilidade, ao mesmo tempo em que permite uma maior difusão e capilaridade mercantil em diversos lugares do planeta, a computação em nuvem é mais do que uma tendência, para muitos negócios e empresas é uma questão de sobrevivência em médio e em longo prazo.

- Ser digital importa: as organizações de futuro precisam adaptar-se às novas formas de relações de trabalho sobretudo nas que o algoritmo e a inteligência artificial são atuantes e contribuem para tomadas de decisão.

- Mindset da Industria 4.0: adaptar-se aos novos conceitos de uma indústria com base na tecnologia e na consciência ecológica organizacional, voltada para uso sustentável dos recursos e na promoção do bem-estar coletivo em que essa organização está instalada.

- Gestão do conhecimento: fomentar pesquisa e desenvolvimento dos talentos e do conhecimento produzido pela organização de tal modo a promover pessoas, comunidades e também os stakeholders. Determinar que a Gestão do Conhecimento é parte integrante do planejamento estratégico de curto, médio e longo prazo, convertendo capital intelectual em produtos, bens e serviços que possam ser valorados em toda a dimensão da organização e com o reconhecimento da sociedade. Um ponto preocupante no tocante ao gerenciamento do conhecimento é a atenção para a não precarização do 
trabalho desenvolvido pelos colaboradores, bem como a atenção total para evitar a alienação dos colaboradores ou descaso com a cultura organizacional.

- Capacidade de liderança e inovação: fomentar projetos que possam ser rapidamente incorporados como inovação tecnológica nos processos a fim de alavancar a capacidade de liderança da organização, otimizando os processos, com possiblidade de redução de custos e baixos impactos ambientais, promovendo a capacidade de liderança.

- Direito eletrônico ou cibernético: Agora até mesmo as questões judiciais estão informatizadas. Os operadores do direito precisam saber de programação de computadores, cibernética e questões afins. A justiça se informatiza e acompanha as transformações sociais atuais no tocante as Tecnologias da Informação e do conhecimento (TICs). Ações e discussão no campo do direito relacionadas a subordinação algorítmica, economia compartilhada, direitos autorais, ações digitais, audiências virtuais (síncronas ou assíncronas) são uma realidade dentro das empresas. O compliance cada vez mais avança em direção ao digital.

- Marketing Digital: As empresas sabem e ainda estão aprendendo que não basta ter apenas pontos fixos de venda. O tradicional balcão não basta. As redes sociais, os sites, blogs e tudo que a internet oferece como canal de venda tem que ser explorado ao máximo para impulsionar a força de venda.

- Empresas que aprendem: As organizações que possuem um planejamento do seu capital intelectual e que de alguma forma gerenciam o conhecimento em suas estruturas internas, consolidam uma maior vantagem na medida que fomentam pesquisas e desenvolvimento apoiados por sobre o conhecimento que é gerado e aplicado na produção de bens e serviços inovadores.

Por conseguinte, o desafio dos administradores, gestores ou líderes na atualidade difere e muito da antiga que se pautava na burocracia como fonte de vantagem competitiva. Uma nova ecologia organizacional precisa ser uma constante nas práticas da administração contemporânea. Como elucidam Silva, Santos e Macedo (2019, p. 150): "Em suma, a ecologia organizacional parte da premissa de que, assim como ocorre na natureza, as organizações passam por uma intensa seleção 
ambiental, o que gera uma situação de elevada competitividade e necessidade de flexibilização de estruturas e processos internos."

$\mathrm{Na}$ mesma linha de compreensão, um fator preponderante é o das questões relacionadas à gestão de pessoas dentro desse novo universo. Uma das arestas desse intrincado prisma é a de administrar o capital humano. Cada vez mais pessoas representam o que há de maior valor dentro das organizações. São pessoas que podem ser disruptivas, que podem inovar e criar desequilíbrios capazes de trazer valor para as organizações.

\section{CONCLUSÃO}

O rumo dos negócios é digital, isso é um fato. Mas afinal, qual o papel da gestão nesse processo? Compreender como administrar ou gerenciar todo esse intrincado quebracabeças é o desafio para administradores, gestores ou líderes das organizações empresariais.

Tudo aponta que as tecnologias de informação ou conhecimento quando não são as estruturas fundantes são o meio para que existam negócios. De uma forma ou de outra, é inegável o poder da tecnologia digital nos processos das empresas nesse momento da história. Inúmeros setores da economia já estão na era digital e outros estão em processo de migração, o que exige dos executivos das organizações muito mais do que apenas os conceitos tradicionais da administração. Novos negócios exigem uma capacidade de aprender rapidamente a compreender os cenários colocados e a tomar decisões que tem impactos estruturais em médio e em longo prazo.

Pensar e agir de maneiras disruptivas é o mindset da administração contemporânea. Ser capaz de adaptar as organizações em situações de constante mudança e de aplicação da tecnologia como parte fundamental dentro das organizações, como é o caso da eletrônica, das telecomunicações, da robótica e até da inteligência artificial, para consubstanciar as decisões, tudo isso somado é agora uma realidade que não se pode retroceder. 
Administrar com escassez de recursos, mercados altamente voláteis, consumidores com demandas ainda indefiníveis, e ávidos por produtos ainda não inventados; gerenciar cadeias de produção geoespacialmente dispersas, com multiculturas envolvidas; além de lidar com questões econômicas, sociais e políticas que tem impacto direto nos planejamentos, é uma verdade constante na vida dos executivos. Não obstante, a realidade cada vez mais exige dos executivos a condução das empresas para uma nova ecologia, na qual o que no passado era desapercebido ou até negligenciado, agora faz parte da atenção e da decisão dos administradores, gestores e líderes das organizações contemporâneas.

Com efeito, também há o gerenciamento do capital intelectual dentro das organizações que agora tem um imenso valor e representam, de fato, o que pode criar disrupção e podem inovar diante de todo esse universo digital que se impõe para as organizações.

A pedra angular de uma transformação digital é a capacidade de responder com agilidade, eficiência e eficácia frente a tamanha mudança e impacto dentro e fora das organizações que queiram se posicionar estrategicamente e terem vantagem competitiva agora e no futuro.

Mas afinal qual o papel da gestão nesse processo? Para os administradores que estão agora na era digital uma afirmação: adaptar-se apresenta-se até o momento como a melhor resposta possível.

\section{REFERÊNCIAS}

ALECRIM, Emerson. Apple é a $1^{\underline{a}}$ empresa dos EUA com valor de mercado de US\$ 1,5 tri. Tecnoblog, 10 jun. 2010. Disponível em: https://tecnoblog.net/345057/appleacoes-valor-mercado-1-5-trilhao-dolares/. Acesso em: 10/09/2020.

ANSOFF, H. Igor. A nova estratégia empresarial. São Paulo: Atlas, 1990. 
BCG Model. Value Based Management.net, c2019. Disponível em: https://www.valuebasedmanagement.net/methods_bcgmatrix.html. Acesso em: 10/09/2020

DRUCKER, Peter Ferdinand. Uma era de descontinuidade. São Paulo: Zahar Editores, 1969.

KAPLAN, Robert Samuel; NORTON, David P. A estratégia em ação: balanced scorecard. Tradução de Luiz Euclydez Trindade Franzão Filho. 19. ed. Rio de Janeiro: Campus, 1997.

KAPLAN, Robert Samuel; NORTON, David P. The Balanced Scorecard - Measures that drive performance. Harvard Business Review 70, Boston, n. 1, Jan./Feb., 1992.

MEGGINSON, Leon C. Lessons from Europe for American Business. Southwestern Social Science Quarterly, v. 44, n. 1, p. 3-13, 1963.

RABELO, Arnaldo. Matriz BCG, do Boston Consulting Group. Filtros de água. Wikimedia Commons, 26 ago. 2006. Disponível em: https://commons.wikimedia.org/wiki/File:Matriz_BCG.png. Acesso em: 10/09/2020.

SILVA, Mara Rosalia Ribeiro; SANTOS, Ana Sara Leite; MACEDO, Augusto Cezar Moura. Inovação, Sobrevivência e Ecologia Organizacional: Possibilidades de Relação. Revista Administração em Diálogo - RAD, v. 21, n. 2, p. 148-163, 2019.

WESTERMAN, George; BONNET, Didier; McAFFE, Andrew. Liderando na era digital. São Paulo: Makron Books, 2016

\section{APÊNDICE - REFERÊNCIAS DE NOTA DE RODAPÉ}

4. Dashboard é um painel de controle, uma apresentação visual que contém as principais informações do negócio. Essas informações são apresentadas por métricas, dados que podem ser facilmente visualizados e manipulados como intuito de alcançar um ou mais objetivos de negócio. 
5. Datamining é um termo comum nas empresas de futuro e significa minerar dados. As pessoas estão conectadas por uma grande rede, a internet, e seus comportamentos podem ser mapeados e até previstos, essa análise comportamental é realizada a partir do que as pessoas informam em suas redes e buscas em navegadores de pesquisa bem como comportamentos relacionados a compras e assuntos de interesse.

6. Essa ferramenta de gestão, denominada Balanced Scorecard, foi desenvolvida por Robert Kaplan e David Norton. "Balanced Scorecard, organizado em torno de quatro perspectivas distintas - financeira, do cliente, interna e de inovação e aprendizado. $O$ nome refletia o equilíbrio entre objetivos de curto e longo prazos, entre medidas financeiras e não-financeiras, entre indicadores de tendências (leading) e ocorrências (lagging) e entre as perspectivas interna e externa de desempenho.". (1997, p. VIII, grifo do autor).

7. Indústria 4.0 pode ser entendida como uma forma inovadora de transformar bens e serviços. Essa nova indústria converge máquinas consideradas inteligentes (que utilizam robótica e inteligência artificial), associando-as às análises computacionais de alta complexidade e ao trabalho colaborativo com pessoas hiperconectadas. Essa indústria busca eficiência em todas as etapas de produção com foco na redução de custos e na administração total da cadeia produtiva, com ênfase no cuidado extremo com a logística que está totalmente integrada aos conceitos de Just In Time, bem como um zelo total com o meio ambiente e com as comunidades envolvidas. Possui, via de regra, uma planta industrial altamente conectada digitalmente, integrada com processos de automação e em total sintonia com conceitos de descentralização dos processos produtivos. Uma característica da Indústria 4.0 é a sua sinergia com todos os stakeholders e sua capilaridade e conexão com o seu mercado consumidor.

Enviado: Novembro, 2020.

Aprovado: Novembro, 2020. 